\title{
The Reform and Exploration of Japanese Reading Instruction Methods from the Perspective of the Psycholinguistics
}

\author{
Wei YIN \\ Foreign Languages College, Zaozhuang University \\ Shandong, 277160
}

\begin{abstract}
Reading is a complex mental activity, a "guessing game based on the psychological languages" rather than a process of passively decoding from the view of psycholinguistics. Starting from the universal problems exist in students' Japanese Reading, the thesis points out the drawbacks of traditional Japanese reading instruction mode, analyzes the feasibility of psycholinguistics' schema theory in the Japanese reading, combines with the specific cases in the teaching of New Japanese Extensive Reading to enrich the linguistic schema of students, replenish their content schema and construct their formal schema in aspects such as setting the group sharing, importing the culture background, introducing online reading, arranging the reading tasks and analyzing the text structure to finally realize the reform and innovation of the Japanese reading instruction.
\end{abstract}

Keywords-Psycholinguistics; Japanese reading; Reform of instruction methods; Schema theory

\section{INTRODUCTION}

As one of main courses with the purpose to train the students' reading comprehension and foreign language thinking logic, the Japanese reading is aimed at cultivating the students' ability of thinking for the comprehensive analysis and inference, enriching their knowledge quantity, expanding their horizons and improving their reading comprehension ability. But combined with the experience of authors and universities' peers, the students' points of losing scores in the Japanese proficiency examination, TJM4 and TJM8 examinations mainly concentrate on the reading part, they seem to do the full-length reading with knitted brows and are often inclined to look up the Chinese information. The slow reading rate, poor reading comprehension ability and narrow reading range and deficient reading interest and other problems universally exist among these students who are learning Japanese. How to change the current status, inspire the reading interest, enrich the reading quantity and improve the reading comprehension ability? Firstly, the drawbacks and deficiencies in the traditional Japanese reading instruction mode are discussed hereinafter.

\section{THE DRAWBACKS IN THE TRADITIONAL JAPANESE READING INSTRUCTION MODE}

(1) The classroom teaching idea is behindhand, and confused with the basic Japanese teaching. Teachers still put the emphasis on explaining the grammar, words and basic knowledge based on the single mode "Words - Sentence pattern - Text - Exercises", often explain the basic knowledge in Chinese in the class, can't lead the students into the scenario of reading materials, and make students lose the reading interest.

(2)The instruction methods and means are simple. They are mainly focused on the instructions by teachers without the interaction and emphasis on training the students comprehensive thinking ability and improving the language output capability. Students only complete the preview before class and exercises mechanically, and don't gain the new knowledge or improve their ability for finding and thinking problems from Japanese reading.

(3) Stronger utilitarian and higher value on exam-oriented education. Teachers often assign a lot of reading exercises for the ability examinations, but these exercises have stronger exam-oriented features without practicability and interestingness. Students fail to realize the "Pleased Reading", and on the contrary, they are more likely to be swayed by considerations of gain and loss and prioritize the results of examinations.

(4) Old-fashioned teaching content and absence of the cultural background knowledge input. Most teachers are confined to the text explanation in class without the relevant cultural background knowledge input and the extracurricular reading material supplement, and the knowledge capacity and depth of the students are smaller to the disadvantage of expanding their horizons.

(5) Less or no extracurricular reading tasks, which cause the students to put less emphasis on the reading.

(6) Simple evaluation mode. The students' reading ability is evaluated only based on the results of the final examination without the comprehensiveness and objectiveness. In such case, the students often only prioritize the results of examinations and neglect the daily reading. 


\section{THE FEASIBILITY OF IMPLEMENTATION OF PSYCHOLINGUISTICS' SCHEMA THEORY IN THE JAPANESE READING}

Reading is the process of handling and inferencing the input information rather than the process of passively receiving information, which is an active and dynamic communicative behavior. How to mobilize the existing knowledge system and thinking mode formed in their brain to comprehend, handle, analyze the reading materials to further inference the logic relations and understand the intention of the author is vital for readers. Although the words, grammar and other basic knowledge can affect the reading comprehension activities, if the reader who has firmly grasped the basic language knowledge can't positively utilize the existing cognitive structure to objectively analyze and handle the reading materials, his / her comprehension ability of Japanese article will be relatively weak. Reading is one complex mental activity and one "guessing game based on the psychological languages" rather than one process passively decoded from the view of psycholinguistics. Moreover, the "schema theory" has been promoted and applied in the text reading instruction of numerous foreign languages. Under the cognitive development theory of Piaget, the schema refers one organized and repeated behavior mode or mental structure, and one unit of cognitive structure. From the view of psycholinguistics, the schema theory can explain the reasons why most Japanese reading methods can't obtain the significant effect and become boring. We should consider the reading activities as one subjective and initiative cognitive activity, stimulate and construct the students' schema structure, the much more perfect schemas there are, the higher reading efficiency there will be. In the reading field, the schema theory can be divided into linguistic schema, content schema, formal schema, etc. The linguistic schema refers to the proficiency degree of words, glossaries and other basic language knowledge, the content schema refers to the degree of familiarity with the article's subject and background knowledge, and the formal schema refers to the comprehensive degree of the article's style, of which the linguistic schema is the premise and the content schema is the key. Furthermore, our students' reading disorder and poor reading ability can be ascribed to that we often excessively put the emphasis on the accumulation and construction of linguistic schemas and always ignored the content schema and formal schema in the past reading instruction. The author will discuss how to reform the mode of Japanese reading instruction in combination with the experience in the reading instruction.

\section{THE REFORM AND EXPLORATION OF JAPANESE READING INSTRUCTION METHODS FROM THE VIEW OF THE PSYCHOLINGUISTICS}

(1)Enrich the students' linguistic schema and establish the language sense. Specific to the article topics, set up the sharing tasks in groups, improve the students' ability to look up materials and organize language, for example, let students look up and share the relevant information of Mount Fuji in Japanese, then let other groups supplement and pose questions in the instructing process of the Lesson IV Mount Fuji is Still Alive in the New Japanese Extensive Reading Volume III, the students can accumulate new words and grammar in the search process. The teaching \& facilitating classes in Japanese can help students adapt the Japanese environment, eliminate the psychological obstacle to the long Japanese articles, accumulate and flexibly apply the basic Japanese knowledge.

(2)Construct and enrich the content schemas of students. The author considers that the aspect is vital to improve the reading ability of students and can affect the Japanese thinking formation of students. As for Chinese students, there are many students with higher academic performance confused in the reading process: Why there are always deviations, and misunderstanding in the mastering the author's opinions and subject in one article even after the clear comprehension?

\section{A. To import the relevant cultural background knowledge, and instruct students to read materials by the Chinese- Japanese comparison method.}

Reading activity is aimed at understanding the topics and context of one article with the foreign thinking and in combination with the accumulated cultural background knowledge under the premise that certain language knowledge has been mastered, rather than one simple process from bottom to top [3]. Any national language is also the carrier of the national culture [4], reading is really not the pure language conversion, when the reader can't understand the cultural background reflected and hidden in the reading materials, he / she certainly can't correctly grasp the topic thinking of one article, even fails to reasonably infer and effectively extract the key information in the article in the event of new words, long and difficult sentences and other interference information. How to construct and enrich the content schemas of students is crucial.

The teachers can set up questions in the knowledge import link, and meanwhile compare the similarities and differences between Chinese and Japanese, stimulate the students' interests in the home culture and improve their cultural confidence, and it is also indispensable to import the Chinese culture when the foreign language learner shows the phenomenon of home culture dumbness. When familiar with the home culture, the foreign language learners also serve as the important role "Let the Chinese culture go out" in the cross-cultural communication. For example, in the instructing link of Lesson 25 The "Sense of Seasons" in the New Japanese Extensive Reading Volume II, the teacher can set up Japanese questions "Why Japanese people always speaks the weather greetings? What are the 'Time' greetings used by Japanese people in the letter reflect? What is the attitude about the seasonal transition of Japanese people? What are reflects about the sense of seasons of Japanese people in the real life? Think the expression of sense of seasons in the Japanese anime and cultural works." Questions must be set step by step to gradually induce students into the thinking and scenario of the article topics, encourage students to answer in Japanese, and randomly change the questions with the answer of the students. Later, the teacher can ask what is the Chinese's sense of seasons? How much do you know about the crystal of Chinese workers' wisdom - the 24 solar terms? Do you know that the 24 solar terms have been included in the intangible cultural heritage by the United Nations? What's the reason? Why did Japan has fully absorbed the 24 solar terms and marketed them on the 
Japanese calendar? Whether it can reflect the influence of our Chinese culture?" , guiding the students with the comparison thinking of the Chinese and Japanese cultures can impress the students, enrich their understanding about the background knowledge of the Chinse and Japanese cultures, and improve their confidence and pride in the home culture. After the lesson, students can understand the geographical conditions and weather conditions in Japan, the natural view of Japanese people, "Seasonal Words" and "Season Words Collection" in the Japanese classical poetries, the "Mono No Aware" literature represented by Kawabata Yasunari and the national character that Japanese loves nature, the slender character of Japanese, etc. referred in the Ten National Characters by Japanese Litterateur Haga Shizhiyi, and realize the extensive and profound Chinese culture as well as the acceptance and transfiguration of Chinese culture in Japan.

Due to special attention to this link, the author could look up mass relevant materials, think the import methods and relations among questions, inspire the thinking, and stimulate the existing formal schema structure of students. The teacher should adopt the instruction mode centered on the discussion rather than the teaching, encourage students to discuss in groups, make up for deficiencies, and alternatively insert his own comprehension by combining with the understanding of students. Students can also master the usage of new words and word groups, and then flexibly use them to realize the purpose of language output.

\section{B. Teaching tools should include other readings and video material, not just textbooks.}

The teacher can utilize the multimedia to allow students to read the online reading materials within the specified time to realize the internet + reading. Students can read the articles released on the Japanese learning APP, such as People's Daily Online in Japanese, Tensei Jingo and Japanese Listening and Translation Learning to learn about the latest China-Japan era topics and accumulate the quantity of vocabulary. In the Lesson 6 "Shopping" of New Japanese Extensive Reading Volume III, the teacher put the following question to students at the beginning: "How do you consider about the view that the Japanese is the shopping nation referred in the text?" Student replied "I don't feel, but the Chinese maybe the shopping nation today" with the dubious attitude. Specific to the confusion, the teacher led students to read some articles published on the People's Daily Online, of which one article pointed out that the Japanese 30 years ago is exactly the same with the oversea "explosive shopping" of the Chinese exposed a few years ago, and interviewed the female shoppers who had the oversea "explosive shopping" in that year, they also mentioned the "explosive shopping" phenomenon of the Japanese in that year and pointed out that the Japanese also showed the bad behaviors in the oversea travel in that year. The teacher not only enables students to deeply comprehend the text, accumulate numerous new words such as "Alipay", "QR code", "China new four inventions" and "Double Eleven", but also empathically realize the changes in the consumption view and methods of contemporary people and the impact of Internet on our lives by means of playing the Japanese report about the "explosive shopping" of the Chinese in Japan, and the news and programs relevant to the online "explosive shopping" during the Double Eleven, etc. including the influence of Double Eleven on Japan, the popularization of Alipay in Japan, and the public opinions of the Japanese in class.

\section{Assign the extracurricular reading tasks.}

At the beginning of the semester, the teacher can provide the students with the list of books to be read, let them select randomly and submit the reading report. Different kinds of book can be provided for students in different grades, for example, books in Chinese (such as The Chrysanthemum and the Sword) or short articles such as simple Japanese legends and folk cultures can be provided to the freshmen, so that they can learn about the Japanese social culture and their mode of thinking. For the students in the second year of college, the teacher can recommend some popular fictions easily understood, such as some works made by Higashino Keigo or other books written both in Chinese and Japanese. These books can cultivate the language sense and reading habits of students to improve their reading speed. In the third year of college, the students could learn A History of Japanese Literature, An Introduction to Japanese Linguistics and other specialized courses, and they can read the classical literatures such as Kawabata Yasunari, Natsume Soseki and Haruki Murakami to feel the charm of Japanese literature and the influence of classical Chinese literatures on Japanese literature and improve their literature quality. Alternatively, they can read the books relevant to Japanese culture and language to learn about the features of Japanese Of course, the teacher should consider the learning condition, and encourage students to search the books compatible with personal reading ability.

The teacher should also lead the students to master the text context through the discourse analysis, find out the text thought, help them construct the formal schema based on the article style features, and supplement the exercise relevant to the inference and the effective selection and mastery of key information in the article. In studying the psychology of reading, the articles can be divided into the micro-proposition, the macro-proposition and the horizontal superstructure. [5] Such explanation reflects that it is vital for readers to find out the sentence coherence by comprehending the meanings and corrections of sentences [6]. The discourse analysis can help students master the objective of one article and understand the attitude of the author at a macro level, and deliberate the context logic at a micro level.

New Japanese Extensive Reading covers the society, culture, economy, politics, literature, thinking and other contents, fiction, exposition, argumentation, prose, narration and other styles, for example, in the process of argumentation teaching, the teacher can lead students to comprehend the features of argumentation, requiring them to present the thesis and arguments, summarize the thesis or present the thinking, expectation, etc. The teacher shall alternately insert the explanation and practice of reading skills in the reading instruction to help the students eliminate the interference caused by the fuzziness of word meaning and effectively master the topics and key points in the article. The teacher enables the students to discuss how to analyze the long and difficult sentences to overcome the obstacles against the long 
and difficult sentences, and how to infer the meanings of new words to cultivate the students' logic inference ability and enhance the interaction among students and between students and teacher.

\section{CONCLUSION}

Reading is not only the handling process of word language, but also the decoding, inferring and comprehending process of text based on the existing cognitive structure and background knowledge, and many students majored in Japanese give the feedback that the cultural interference and insufficient inference ability in the reading process can obstruct the speed and correctness of reading comprehension, the students shall accumulate the cultural background knowledge at the time of language in taking to construct and develop their reading schema. The teacher introduces the network reading into classes by means of modern teaching models, combine with the program teaching method to let the students complete the reading program in groups, and train the language output, logic inference and innovation capacity of students. The reform of Japanese reading instruction from the view of psycholinguistics can get rid of the drawbacks in the traditional Japanese, conform to the cultivation objective of composite applicationoriented talents advocated in the innovation-oriented society, and instruct us to have various reforms and innovative attempts in Japanese reading instruction.

\section{REFERENCES}

[1] Yan JIN. The Exploration on the Instructional Improvement of College Japanese Extensive Reading [j]. Journal of Changchun University of Science and Technology (Higher Education Edition), 2009(11): 161.

[2] Rong XUE. Schema Theory and its Application in the Reading Instruction [j]. Journal of Anhui University of Technology (Social Science Edition), 2001(3): 81.

[3] Hongyu HE Reading Interactive Theory and College English Reading Instruction [j]. Science and Technology Information, 2012(32): 201.

[4] Jianxin ZHU. Language Input and Cultural Adaptation - College English Reading Instruction Methodology [j]. English Teaching and Research, 2008(10): 50 .

[5] Biyin ZHANG. Psychology of Reading [M]. Beijing, Beijing Normal University, 1996.

[6] Ai ZHANG. Role of Discourse Analysis in Japanese Reading [j]. Journal of Tianjin Polytechnic University, 2002(6): 81 